(Print) ISBN : 978-602-73114-4-2

\title{
PELATIHAN SPIRITUALITAS MISI BAGI MAHASISWA SEKOLAH TINGGI TEOLOGI (STT) EKUMENE JAKARTA
}

\author{
Raja Oloan Tumanggor \\ Fakultas Psikologi Universitas Tarumanagara Jakarta \\ Email: rajat@fpsi.untar.ac.id
}

\begin{abstract}
Abstrak
Dalam psikologi agama spiritualitas memegang peranan penting dalam kehidupan manusia. Spiritualitas adalah jawaban manusia atas panggilan rahmat Tuhan agar memiliki relasi dengan diriNya sendiri, dan relasi dengan kekuatan tertinggi ini memungkinkan seseorang berkarya di dunia. Spiritualitas menjadi kekuatan penting yang bisa menggerakkan seseorang melakukan sesuatu. Sementara spiritualitas misi (pewartaan Kabar Gembira) secara khusus menyangkut apa yang perlu untuk berkarya dalam misi. PKM ini menyasar sebuah komunitas akademis, yakni 24 orang mahasiswa Sekolah Tinggi Teologi (STT) Ekumene Jakarta yang mengalami persoalan dalam melaksanakan pewartaan Injil (Kabar Gembira) di tengah-tengah masyarakat. Persoalan itu berupa kurangnya pemahaman mengenai spiritualitas misi, sehingga dalam pelaksanaan misi di lapangan kerap dilatar belakangi oleh motif-motif pribadi seperti mengejar popularitas dan material. Kedua, persoalan dalam bentuk berkomunikasi dan berelasi dengan orang lain yang berbeda latar belakang agama dan budayanya, sehingga saat melakukan kegiatan misioner kerap menimbulkan kesalahpahaman yang berujung pada konflik sosial. Maka dalam program PKM permasalahan ini hendak diatasi dengan mengadakan pelatihan spiritualitas misi bagi para mahasiswa STT Ekumene Jakarta. Dengan pelatihan ini para mahasiswa diberi pemahaman yang komprehensif mengenai spiritualitas misi dengan menggali dasar-dasar yang mendorong mereka melakukan karya misi, menggali motivasi terdalam mereka, siapa menjadi tokoh idola mereka dalam melaksanakan karya misi. Selain itu mereka juga dimampukan untuk menyadari budaya sendiri yang bisa dijadikan aset dalam pelayanan masyarakat. Dengan demikian mereka menjadi mampu menilai pelayanan praktis misioner yang sedang mereka laksanakan saat ini.
\end{abstract}

Kata-kata kunci: spiritualitas, misi, STT Ekumene, PKM.

\section{Pendahuluan}

Untuk bisa melakukan kegiatan pewartaan Kabar Gembira (Injil) diperlukan spiritualitas yang menjadi pendorong dan penyemangat dalam melaksanakannya. Apa itu spiritualitas? Spiritualitas berasal dari kata "spirit" artinya roh. Jadi spiritualitas berhubungan dengan roh yang menjadi penyemangat dan pegangan seseorang dalam melaksanakan sesuatu. Menurut Stephen Bevans (2013) spiritualitas dipandang sebagai semacam kerangka (framework/set) dari nilai, simbol, doktrin, sikap dan praksis, dengannya seseorang atau kelompok mencoba hidup di dalam situasi tertentu, untuk bertumbuh dalam kasih Tuhan. Sebetulnya spiritualitas menyangkut semua orang baik yang percaya pada Tuhan maupun tidak. Maka spiritualitas sifatnya sangat personal. Oleh karena itu ada bermacam-macam spiritualitas sesuai dengan keyakinannya. Orang dapat mengembangkan spiritualitasnya sendiri. Di lingkungan kekristenan juga dikenal spiritualitas yang sudah dibangun dalam bentuk sistem, misalnya spiritualitas awam, spiritualitas tarekat seperti Benediktin, Fransiskan, Jesuit dll. Lalu spiritualitas yang berhubungan dengan misi (kegiatan pewartaan Injil/Kabar Gembira) dinamakan: spiritualitas misi. Apa yang dimaksud dengan spiritualitas misi?

Spiritualitas misi adalah spiritualitas yang dianut oleh seseorang yang ingin bertumbuh dalam kegiatan pewartaan Injil/Kabar Gembira. Kegiatan ini merupakan bagian dari partisipasi seseorang dalam misi Allah. Spiritualitas misi pada dasarnya adalah spiritualitas kristen yang dihidupi dengan penuh kesadaran akan misi Allah (missio dei). Spiritualitas misi terwujud dalam praksis misi di lapangan (dunia). Pada prinsipnya spiritualitas misi adalah pengalaman akan Allah yang hidup sebagai pribadi dalam komunitas melalui kekuatan Roh Kudus untuk bersaksi dan melayani bagi sesama (Ma \& Ross, 2013). Namun, sebetulnya tidak ada model spiritualitas misi yang bisa diterapkan untuk segala situasi dan konteks. Karena situasi dan konteks 
yang dihadapi oleh para pewarta Injil/Kabar Gembira selalu berbeda-beda, maka spiritualitas misi - sama halnya dengan misi itu sendiri - selalu dan dimana-mana merupakan spiritualitas konekstual (Bevans, 2013). Artinya, spiritualitas misi itu tergantung pada tempat dan kondisi dimana seseorang itu berkarya, misalnya spiritualitas misi di negara miskin di Afrika atau Amerika Latin berbeda dengan spiritualitas misi yang ada di Indonesia, karena konteksnya memang berbeda.

Pewartaan iman (misi) kristen tidak lepas dari spiritualitas misi. Bila diperhatikan jumlah penganut Kristen di Eropa setiap tahun mengalami penurunan. Menurunnya populasi kristen di Eropa tentu memiliki kaitan dengan menurunnya pewarta iman yang memiliki spiritualitas misi. Tidak mengherankan situasi kekristenan yang mengalami kemunduran di Eropa akan berakibat juga di Indonesia, bila para pewarta iman Kristen tidak dibekali dengan spiritualitas misi yang memadai. Itulah sebabnya pelatihan spiritualitas misi bagi para mahasiswa STT Ekumene Jakarta menjadi relevan, karena mereka merupakan ujung tombak dalam pewartaan iman kristen.

Mahasiswa pasca sarjana Sekolah Tinggi Teologi (STT) Ekumene Jakarta adalah sekelompok orang yang sedang menempuh studi lanjut bidang teologi (ilmu ketuhanan). Mereka terdiri dari pendeta, guru agama, penatua jemaat, dan gembala, yang sehari-hari melakukan kegiatan pewartaan Injil/Kabar Gembira di tengahtengah masyarakat. Setelah selesai studi lanjut, mereka akan kembali ke komunitasnya masing-masing. Menarik, bahwa mereka melakukan kegiatan misi (pewartaan Injil/Kabar Gembira) dengan cara yang berbeda-beda. Para pendeta bekerja di tengah-tengah jemaatnya, sementara para guru mengajar agama di sekolah-sekolah. Penatua jemaat juga melayani di tengah umat pada waktu tertentu selain harus mengerjakan tugas utama mereka sebagai karyawan atau pengusaha. Mereka berasal dari institusi gereja yang berbeda-beda dengan aliran teologi yang berbeda juga. Perbedaan aliran teologi ini berakibat juga pada perbedaan pemahaman mengenai spiritualitas misi. Melalui pelatihan ini diharapkan para mahasiswa semakin menyadari apa yang menjadi pendorong (motivasi) mereka melakukan karya/tugas pekabaran Injil/Kabar Gembira di tengah-tengah jemaat.

\section{Metode Pelaksanaan}

Metode pelaksanaan program pelatihan ini dilakukan dengan pendekatan partisipatif, pendekatan kelompok, pendampingan individual, metode ceramah, dan metode dialog/tanya jawab. Pendekatan partisipatif bermaksud agar peserta pelatihan dapat berpartisipasi selama kegiatan dari awal hingga akhir. Diadakan juga kerja dan diskusi kelompok untuk berbagi pengalaman satu sama lain. Materi disampaikan dalam bentuk ceramah dan dialog, agar terjadi interaksi antara peserta dengan fasilitator pelatihan.

Tahapan atau langkah-langkah yang dilakukan untuk melaksanakan solusi atas permasalahan yang dihadapi oleh para mahasiswa STT Ekumene tersebut adalah pertama-tama mendata persoalan apa saja yang mereka hadapi dalam melaksanakan karya misi (pewartaan Injil/Kabar Gembira) di dalam komunitas jemaat mereka masing-masing. Setelah masalah mereka dipetakan, kemudian dilanjutkan dengan pemaparan materi pelatihan. Selama pemaparan materi, peserta juga diberikan kesempatan untuk bertanya mengenai sesuatu yang belum jelas dan mereka juga diperbolehkan menyampaikan gagasan/pemikiran mereka mengenai soal yang dibahas tersebut. Selama pemaparan materi juga diberi kesempatan untuk menonton film mengenai pemahaman misi yang berobah dari waktu ke waktu dan dilanjutkan dengan tanya jawab.

Selanjutnya para peserta diberi kesempatan untuk membagikan pengalaman pribadi dalam melaksanakan karya misioner mereka. Pada tahap akhir pelatihan diadakan evaluasi atas seluruh kegiatan yang telah dilakukan dan dari hasil evaluasi ini akan ditindaklanjuti program apa lagi yang perlu dilaksanakan di lingkungan tersebut di masa mendatang.

\section{Hasil dan Pembahasan}

Pelatihan spiritualitas misi yang diikuti oleh 24 mahasiswa STT Ekumene Jakarta diawali dengan doa pembukaan. Pada tahap awal sebelum sampai ke sesi penyampaikan materi terlebih dahulu diminta peserta untuk mengisi angket spiritualitas misi. Angket terdiri dari 12 item pertanyaan. Pertama menyangkut informasi pribadi seperti tempat dan tanggal lahir, nama gereja, profesi utama, pendidikan dan sejak kapan melaksanakan kegiatan misi (no 1-5). Kemudian mereka diminta menyebutkan kutipan Kitab Suci yang 
menjadi pendorong mereka melakukan karya misi (no.6), baru diminta merumuskan motivasi utama (no.7) dan tokoh idola mereka melaksanakan misi (no.8). Pertanyaan berikut (no.9) mereka diminta menanggapi bagaimana peran budaya dalam pelayanan misi. Lalu disusul dengan pandangan teologis yang menjadi pegangan mereka bermisi di tengah masyarakat (no. 10). Sementara dua pertanyaan terakhir menyangkut kegiatan praktis apa yang mereka lakukan dalam mengembangkan pelayanan misi (no. 11) dan menyebutkan contoh karya misi yang sedang mereka lakukan saat ini (no. 12).

Kalau dilihat latar belakang pendidikan, para peserta umumnya berasal dari latar belakang pendidikan teologi dan saat ini sedang menempuh studi S2 dan S3 teologi. Mereka umumnya sudah memiliki profesi entah sebagai guru agama, dosen, atau pendeta jemaat. Semua peserta memiliki kutipan Kitab Suci yang menjadi pendorong mereka melakukan karya misi. Hal itu bisa dipahami karena mereka sudah terbiasa dengan kutipan Kitab Suci dalam aktivitas mereka setiap hari. Adapun motivasi mereka melakukan misi beragam seperti kasih Allah, anugerah Allah, tanggung jawab pada Tuhan, Amanat Agung, kemuliaan Tuhan. Sementara tokoh idola mereka pun cukup beragam seperti Yesus, Paulus, misionaris dan malah orang tua sendiri menjadi idola pribadi melaksanakan misi. Hampir semua memandang budaya dapat dijadikan sebagai aset dalam pelayanan misi.

Menyangkut pandangan teologis yang menjadi pegangan melaksanakan karya misi di tengah masyarakat pendapat para peserta beragam. Beberapa pandangan teologis seperti: malaikat bersuka cita karena satu orang berdosa bertobat, menjadi terang dan garam dunia, Allah mengasihi manusia berdosa, pemulihan relasi antara manusia dan Allah, pergilah ke seluruh dunia dan beritakanlah Injil kepada segala makhluk. Pandangan teologis sangat beragam. Hal itu bisa dipahami karena latar belakang gereja dan pendidikan yang berbeda.

Kegiatan praktis yang mereka lakukan dalam mengembangkan pelayanan misi juga beragam. Mulai dari menjalin hubungan yang baik dengan masyarakat sekitar, melakukan bakti sosial, mengajar teologi, melakukan pelatihan, pelayanan karitatif, ikut kegiatan dalam masyarakat. Mereka juga memberikan beberapa contoh pelayanan praktis misioner yang sedang mereka lakukan seperti membagi dan memasak makanan bagi karyawan, bergabung dengan tim misi gereja mereka, mewartakan Injil bagi warga non Kristen di lingkungannya, pendekatan lintas budaya dalam bidang pendidikan dan perdagangan, bercerita tentang hidup pada setiap orang yang ditemui. Setelah mengisi angket para peserta mendapat kajian teori mengenai spiritualitas misi dari nara sumber.

Pertama-tama diungkapkan apa itu spiritualitas misi? Spritualitas adalah cara mengamalkan kehidupan sebagai orang beriman yang berusaha merancang hidup ini seperti Tuhan menghendakinya (Heuken, 2002). Spiritualitas itu bagaikan sebuah sumber dari mana seseorang dapat menimba kekuatan untuk termotivasi melakukan sesuatu (Bevans, 2013). Maka spiritualitas misi adalah segala sesuatu yang menjadi kekuatan dan pendorong bagi seseorang untuk tetap bersemangat dalam melakukan kegiatan pekabaran Injil. Jadi melalui pelatihan ini para mahasiswa diharapkan mampu menggali apa yang mendorong mereka untuk melakukan kegiatan misioner. Semangat ini perlu dibangkitkan agar mereka tetap penuh semangat melakukan pewartaan Injil, kendatipun mereka menghadapi banyak tantangan di tengah-tengah masyarakat.

Spiritualitas berhubungan dengan roh yang menjadi penyemangat dan pegangan hidup seseorang dalam melaksanakan sesuatu. Spiritualitas dipandang sebagai kerangka nilai, simbol, doktrin, sikap dan praksis, dengannya seseorang atau kelompok mencoba hidup dan bertumbuh dalam kasih Tuhan. Spiritualitas menyangkut semua orang yang percaya pada Tuhan maupun yang tidak percaya. Maka ada bermacam-macam spiritualitas sesuai dengan keyakinannya. Orang dapat mengembangkan spiritualitasnya sendiri. Di lingkungan kekristenan juga dikenal spiritualitas yang sudah dibangun dalam bentuk sistem.

Spiritualitas misi adalah spiritualitas yang dianut oleh seseorang yang ingin bertumbuh dalam kegiatan pewartaan Injil/Kabar Gembira. Kegiatan ini merupakan bagian dari partisipasi seseorang dalam misi Allah. Spiritualitas misi pada dasarnya adalah spiritualitas kristen yang dihidupi dengan penuh kesadaran akan misi Allah (missio dei). Spiritualitas misi terwujud dalam praksis misi di lapangan (dunia). Pada prinsipnya spiritualitas misi adalah pengalaman akan Allah yang hidup sebagai pribadi dalam komunitas melalui kekuatan Roh Kudus untuk bersaksi dan melayani bagi sesama (Ma \& Ross, 2013). 
Namun, sebetulnya tidak ada model spiritualitas misi yang bisa diterapkan untuk segala situasi dan konteks. Karena situasi dan konteks yang dihadapi oleh para pewarta Injil/Kabar Gembira selalu berbeda-beda, maka spiritualitas misi - sama halnya dengan misi itu sendiri - selalu dan dimana-mana merupakan spiritualitas konekstual (Bevans, 2013). Spiritualitas misi secara konkrit adalah cara hidup (life style) dari seseorang yang dipanggil dan diutus dalam misi untuk mewartakan Kristus kepada orang lain yang belum mengenalNya. Spiritualitas misi memiliki karisma dan orientasi sendiri.

Bagaimana seseorang mengembangkan spiritualitas bagi para misionaris? Studi empiris (empirical study): studi empiris atas kehidupan spiritual dari para tokoh misionaris dapat menjadi dasar bagi kita untuk membangun spiritualitas sendiri. Berbagi iman (faith sharing): cara konkrit lain mendekati spiritualitas misi adalah dengan membagi pengalaman iman ketika para misionaris membagikan pengalaman misioner dan bagaimana mereka menghidupi panggilan mereka dalam rekoleksi. Biografi/autobiografi misioner: Spiritualitas misi dalam bentuknya yang konkrit dapat dibagikan/ditemukan juga dalam jurnal atau biografi.

Motivasi misioner: Misionaris harus dengan jelas menyadari mengapa mereka merasa terpanggil dalam misi. Sangat membantu mendalami beberapa motif-motif misioner klasik seperti teosentris, christosentris, soteriologis, eklesiologis, asketis dan humaniter. Ekspresi spiritualitas misi adalah teori menghidupi model hidup misioner. Ada beberapa sumber untuk teori tersebut, yaitu: 1) Kitab Suci: Beberapa teks dari PL dan PB memiliki hubungan yang khusus dengan misi. 2) Teologi: misiologi adalah salah satu teologi praktis seperti halnya pastoral. Teologi praktis ini harus bekerja sama dengan dogmatik. 3) Sejarah: seperti halnya biografi misionaris dan penelitian historis dapat menolong mengembangkan spiritualitas misioner.

Semua spiritualitas termasuk spiritualitas misi dipengaruhi oleh konteks budaya. Kita harus mampu membaca tanda-tanda zaman dan menafsirkannya dalam cahaya Injil. Tanda-tanda zaman juga menolong kita untuk menafsirkan Injil. Apa yang terjadi secara global dan lokal memiliki efek bagi hidup kristiani. Perkembangan budaya punya kaitan dengan kekristenan dan spiritualitas misi. Satu perkembangan penting adalah minat yang makin tinggi pada inkulturasi/kontekstualisasi iman di dunia. Kekristenan dari zaman kuno sudah punya kesadaran bahwa iman harus terintegrasi dengan budaya umat yang menerima Kristus.

Satu perkembangan penting adalah situasi dunia yang pluralistis di dalam komunitas kristiani di seluruh dunia. Misionaris ada di tengah perkembangan ini. Sebagai bantuan bagi pemahaman iman dan interpretasi atas situasi multikultural, pengetahuan sosial perlu melibatkan filsafat dalam teologi. Psikologi, sosiologi, antropologi dan ekonomi serta ilmu sosial politik punya peran makin penting dalam memahami bagaimana kehidupan kristen bisa dihidupi dalam dunia zaman "Now".

Setelah pemaparan teoretis mengenai spiritualitas misi, dilanjutkan dengan tanya jawab dan diskusi kelompok.

\section{Kesimpulan dan Saran}

Pada dasarnya spiritualitas misi adalah spiritualitas bagi gaya hidup dalam mengembangkan iman, spiritualitas dalam mewartakan Jesus Kristus dalam cara beragam di antara orang yang belum mengenal Dia. Itulah spiritualitas pencapaian, pergi melewati batas, pengosongan diri, spiritualitas meninggalkan rumah, keluarga, budaya untuk pergi bersama Tuhan dan mencari Tuhan di antara orang lain.

Maka misionaris harus berakar kuat dalam tradisi spiritualitasnya dan mereka harus terbuka berdialog dengan tradisi, roh dan iman orang lain. Misionaris adalah jembatan antara sejarah orang yang terpisah dan sejarah dunia, antara Timur dan Barat, antara abad pertanian dan industri., antara gereja Barat dan gereja dunia. Misionaris harus menjadi model utusan, alat, tamu, dari pada serdadu, kapitalis. Misionaris harus menjadi gambar pembelajar, pencerita panggilan misioner, dari pada menjadi guru, penjual atau hakim.

Pelatihan spiritualitas misi yang diikuti oleh 24 peserta ini mendapat apresiasi positif dari para peserta. Mengingat pentingnya topik yang dibahas dan didiskusikan para peserta mengharapkan agar pelatihan serupa dilaksanakan lagi di hari-hari yang akan datang dengan peserta yang lebih banyak lagi. Pelatihan spiritualitas 
(Print) ISBN : 978-602-73114-4-2

misi sebetulnya tidak hanya perlu bagi para praktisi misi, tapi juga bagi jemaat awam agar semakin banyak orang yang menjadi pewarta di tengah masyarakat.

Ucapan Terima Kasih (Acknowledgement)

PKM yang dilakukan di Sekolah Tinggi Teologi (STT) Ekumene Jakarta pada semester genap 2017/2018 terlaksana berkat bantuan dana dari Direktorat Penelitian dan Pengabdaian kepada Masyarakat (DPPM) Universitas Tarumanagara Jakarta. 
(Print) ISBN : 978-602-73114-4-2

\section{DAFTAR PUSTAKA}

Aguado, M. A. (2010). Mission Spirituality and Care for Creation: An Introduction, in: International Review of Mission, 175-179.

Armstrong, T.D. (1995). Exploring spirituality: The development of the Armstrong Measure of Spirituality. Paper presented at the annual convention of the American Psychological Association, New York, NY.

Benner, D.G. (1989). Toward a psychology of spirituality: Implications for personality and psycholtherapy. Journal of Psychology and Christianity, 5, 19-30.

Bevans, S. (2013). Towards a mission spirituality, in: www.maryknoll.us/home/resources/

Heuken, A. (2002). Spiritualitas Kristiani, Cipta Loka Caraka, Jakarta.

Ma, W. \& Ross, K.R. (eds). (2013). Mission Spirituality and Authentic Discipleship, Regnum, Oxford.

Ponce, R.P. (2012). Transformative Spirituality and Mission, in: International Review of Mission, 322-330. 